\title{
The Science of the Five Elements in the Evolution of Humanity: Primo Vascular System (Bonghan Circulatory System)
}

\author{
Sung Jang Chung \\ Morristown-Hamblen Healthcare System, Morristown, TN, USA \\ Email: sung.chung@comcast.net
}

Received 1 December 2015; accepted 19 February 2016; published 22 February 2016

Copyright (C) 2016 by author and Scientific Research Publishing Inc.

This work is licensed under the Creative Commons Attribution International License (CC BY). http://creativecommons.org/licenses/by/4.0/

\section{(c) (i) Open Access}

\begin{abstract}
In the evolution of humanity, the scientific relationship between the Theory of the Five Elements described in the Eastern philosophy and science of physics, cosmology, evolution, biology and medicine is still not clearly known. Consequently, physicists, anthropologists, biologists and medical scientists have been investigating to find objective proofs and clinical evidences that would elucidate it. In this study, findings and discoveries in sciences of these arenas are examined to find the scientific relationship. The relationship between the Theory of the Five Elements and science of cosmology, evolution, human embryology, traditional medicine, the newly-discovered Primo Vascular System (Bonghan circulatory system), and lifestyles is proposed on the basis of findings in science and in the perspective of the author's hypothesis of the "ultron"-"logotron" theory in this study.
\end{abstract}

\section{Keywords}

Evolution, Five Elements, Confucianism, Jeong Yeok, Traditional Medicine, Primo Vascular System, Ultron-Logotron Theory

\section{Introduction}

In the evolution of humanity, the scientific relationship between the Theory of the Five Elements 五行 described in the Eastern philosophy and science of cosmology, evolution, biology and medicine is still not clearly known (Capra, 1999; Hawking, 2001; Bohm, 2006; Laszlo, 2008; Chung, 2014a, 2014b, 2015a, 2015b). Consequently, physicists, anthropologists, biologists and medical scientists have been investigating to find objective proofs and clinical evidences that would elucidate the scientific relationship. 


\subsection{The Ultron-Logotron Theory}

The author (Chung, 2014a, 2014b) proposed a hypothesis of the "ultron”-“logotron” theory on the basis of review of modern quantum physics and the Eastern philosophy, especially Confucian philosophy in the arena of basic elementary particles and consciousness of mind, and personal experiences of valid precognitive dreams of the author (Penrose, 2005; Penrose, Hameroff, \& Kak, 2011; Griffiths, 2005; Nichol, 2006; Tong, 2009; Ochsner et al., 2002; Schwartz et al., 2005; Close, 2011; William, 1967; Kim, 1885; Yi, 1990; Chung, 2009, 2010, 2014a; Serway \& Faughn, 2000).

The self is the agent being the source of consciousness, and responsible for the thoughts of mind and actions of body of an individual, enduring through time.

The "ultron"-“logotron” theory regarding the scientific relationship between self and consciousness: mind and matter is described as follows:

1) A human individual, the self is composed of the inner self and the physical self/body. The physical self is false and would fade and disappear at death of the body. The inner self is the true self (spirit) and controls the physical self/body, and would continue to live beyond death. The inner self controls the physical self /body by interacting with the prefrontal cortex (neurons) of human brain (Chung, 2012).

2) Valid and undeniable precognitive dreams of the author's personal experiences and quantum entanglement strongly suggest the inner self's potential power transcending the time phases of the past, present and future, and existence of a timeless, nonlocal and holographic consciousness world of reality.

3) The "ultrons" are the building blocks of matter of the universe. The "logotrons" are the building blocks of consciousness of the human mind. The "logotrons" are virtual particles. The "ultrons" and "logotrons” interact each other with mental-force carrying "mentalon” in neurons of human brain. Mentalon exchanges between logotron and logotron or logotron of self's consciousness and logotron of consciousness superpositioned to particles of matter (Table 1 and Table 2; Figure 1).

4) There seem to be parallels between the "ultron”-“logotron” theory and quantum mechanics from the ontological perspectives, and a close agreement between the the "ultron”-“logotron” theory and the Penrose-Hameoff's Orch OR theory (2011) or the von Neumann-Heisenberg's orthodox quantum mechanics (Stapp, 1999, 2011, 2013) that seem to be correct descriptions and applicable to both the inner self and the physical self/body of humanity, respectively on the basis of the human individual self composed of two selves, one, the inner self and one, the physical self (Chung, 2012).

Table 1. Comparison of characteristic aspects of the "ultron”-“logotron” theory and quantum physics.

\begin{tabular}{lll}
\hline \multicolumn{1}{c}{ Characteristic aspects } & \multicolumn{1}{c}{ The "ultron”-“logotron” theory } & \multicolumn{1}{c}{ Quantum physics } \\
\hline Basic elementary particle & Yin- and yang-ultrons & Quarks and electrons \\
Form & A solid and a broken line & An open and a closed string \\
Movement & Join, movement, stillness, advance, retreat, expansion & Split, fission, break, pinch, join, spin and \\
and contraction & oscillation \\
Property & Triple: particle, wave and consciousness & Triple: particle, wave and consciousness \\
Energy & Yes & Yes \\
Force & Yes & Yes \\
\hline
\end{tabular}

Table 2. Comparison of postulated characteristic aspects of "ultron” and "logotron".

\begin{tabular}{lll}
\hline \multicolumn{1}{c}{ Characteristic aspects } & \multicolumn{1}{c}{ Ultron } & Conscious mind \\
\hline Element of & Physical matter & Conscious (spiritual) \\
Nature & Physical & Created by the creator and co-creator (man) \\
Creation & Created by the Creator & Triple: particle, wave and consciousness \\
Property & Triple: particle, wave and consciousness & Virtual \\
State & Real and virtual & Mental-force-carrying mentalon \\
Interaction between themselves & Graviton, electromagnetic force, weak and strong & (Instantaneous) \\
\hline
\end{tabular}




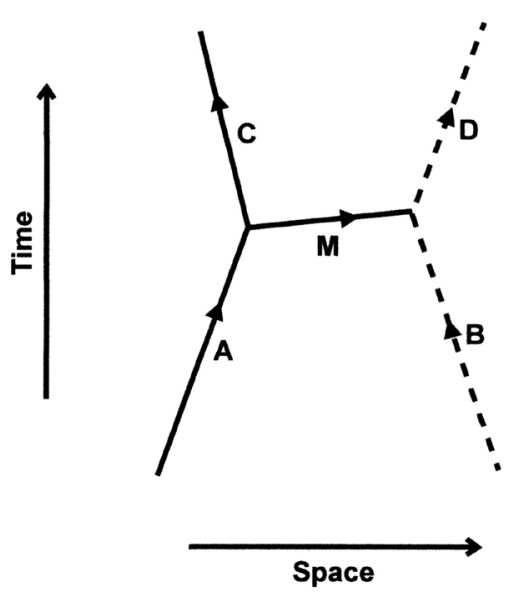

(a)

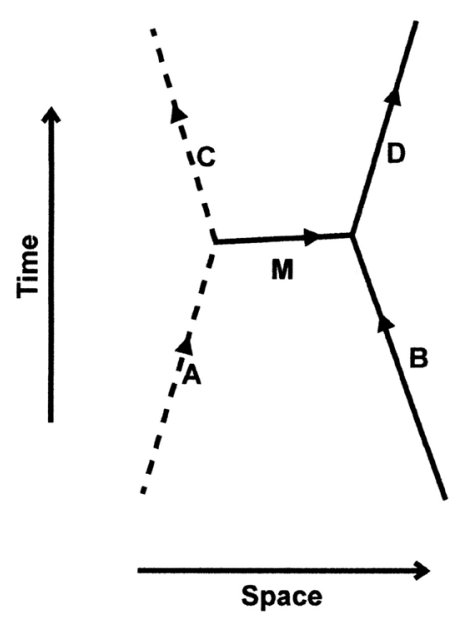

(b)

Figure 1. Feynman's spacetime diagram of interactions between "ultron" and "logotron". (a) A—Real ultron in the excited state in the neuron of the prefrontal cortex caused by incoming stimulus. C-Real ultron in the ground state after collapse of the quantum wave function when the self controls (observes). B-Virtual logotron in the ground state in the neuron of the prefrontal cortex. D-Virtual logotron in the excited state when the self observes and cognizes. M-mental-force-carrying "mentalon" exchanging between ultron and logotron. (b) A-Virtual logotron in the excited state in the self's conscious mind in the neuron of the prefrontal cortex. $\mathrm{C}$-Virtual logotron in the ground state after exchanging mentalon between the logotron and ultron in the neuron. B-Real ultron in the ground state in the neuron of the prefrontal cortex. D-Real ultron in the excited state in the neuron after exchanging mentalon between logotron and ultron. $\mathrm{M}-$ mentalon (see text).

The consciousness world and the spiritual world are conjectured to be nonlocal and timeless worlds (Table 1 and Table 2) as shown by existence of quantum entanglements (Gisin, 2015). Transmission of mental-forcecarrying mentalon is instantaneous.

The author (2015b) has recently published a possible deeper structure of leptons and quarks: yin- and yangultron mass with $0.16 \mathrm{eV}$, electric charge of $\pm 1.602176565 \times 10^{-19}$ coulomb/(3.19 × $\left.19^{-6}-2 k\right)$; $(k$ denotes number of neutrinos in an electron or positron); total number of ultrons as well as yin- and yang-ultrons in a lepton, and an up, down and strange quark.

The "ultron”-“logotron” theory would need further research for its verification.

\subsection{Cosmology and Evolution}

In cosmology and evolution, cosmogenesis, geogenesis, biogenesis and anthropogenesis have been investigated by scientists on the basis of discoveries and findings in quantum physics and archeological fossil researches (Hawking, 1996, 2001; Darwin, 1859, 1874; Teilhard de Chardin, 2008; Lehman \& Persinger, 2015; Haywood, 1995; Maton et al., 1997).

It is inferred in science (Hawking, 1996, 2001) that the universe was created in a Big Bang about fifteen billion years ago. Formations of protons, neutrons, and mesons occurred in cosmogenesis from subatomic fundamental elements, leptons and quarks, and energy, and then generated hydrogen (the most abundant element in the universe) and helium that started to form stars about one billion years after the Big Bang. The planet, Earth was born from the sun about five billion years ago. In the contracting and cooling process of the sun, some of hydrogen and helium were converted into elements of carbon and oxygen out of which our bodies are made.

In the Earth, heavy metal iron descended into the core of the Earth (metalic barysphere) and light oxygen and carbon ascended into the crust of the Earth. The Earth was initially very hot and without the atmosphere. In the course of time, it cooled and the atmosphere was produced by the emission of gases from the crust rocks. Oceans (hydrosphere) (Hawking, 1996, 2001; Teilhard de Chardin, 2008; Campbell et al., 2003) were then formed about four billion years ago.

Primitive forms of life developed in the ocean about three billion years ago, possibly as a results of chance combinations of atoms into large inorganic, organic molecules and self-reproducing molecules, then cells, plants, animals of fish, amphibians, insects, birds, mammals, primates, and ultimately the humans in the evolution of humanity (Hawking, 1996, 2001; Teilhard de Chardin, 2008; Jaybuck \& Lutgans, 2003; Sadava et al., 2011; 
Kinney, 1998).

\subsection{Anthropology}

The author published an article on the basis of his review of findings and discoveries in evolution, anthropology and quantum physics (Joseph, 2011a, 2011b; Teilhard de Chardin, 2008; Nani et al., 2011; Freeman, 2008; Wells, 2007; Gross, 1992; Wolpoff, 2011; Nelson, 2011; Lockeley, 2011; Sonder, 1999; Zhang et al., 2002; Enard et al., 2002; MacAndrew, 2004; Kinney, 1998; Howell, 1973). The following conclusion (Table 3) is proposed in the perspective of his hypothesis of the ultron-logotron theory (Chung, 2014a, 2014b):

1) There seems to be four stages in the evolution of humanity, Homo, Homo sapiens, Homo sapiens sapiens and Homo divina. Since 5,000 BP when early civilizations had been developing on Earth (Janson, 1971; National Geography Society, 1985; Haywood, 1995), Bhagavan Krishna, Fu Hsi, Buddha, Confucius, Jesus Christ and other enlightened saints came and taught the humanity (Yogananda, 2004; Mascaro, 2003; Chung, 2010). The author infers that Homo divina began 5,000 BP and will continue in the future evolution of humanity.

According to Rhawn Joseph (2011b), "more than 90\% of human DNA is dormant and silent and as tens of thousands of silent genes have yet to be expressed. Human evolutionary metamorphosis will likely continue into future. Psychic abilities like ESP and highly increased sensitivities of sense organs would be expectable." "The humans of the future have the evolutionary and genetic potential to be as 'gods'." (Joseph, 2011b; John 10:34, 14:10-14).

2) In Genus Homo, predecessors to Homo sapiens evolved to Homo sapiens that developed large frontal and temporal lobes, further the prefrontal cortex as well as the language gene, FOXP2 200,000 years ago, providing the status of brain that would be ready for human spirit entities to incarnate (Reich et al., 2010; Joseph, 2011b; Zhang et al., 2002; Enard et al., 2002; Lockley, 2011; MacAndrew, 2004).

3) The earliest transmigration, bodily incarnation of human spirit, that is, appearance of Homo sapiens sapiens, modern man seems to have taken place in Africa 120,000 years ago.

4) Homo sapiens seem to be the human ancestor in the evolution.

5) According to Jeong Yeok, the year, 1884 A.D. is Bango 118,643 year, suggesting the dating of the beginning history of humanity.

6) The Darwin's theory of evolutionism and creationism of religion seem to be correct descriptions of the evolution of humanity and the universe for each theory describes different aspects of the humanity and the universe in their evolutions. The Darwinism seems to be applicable in the realm of the physical self/body of man. The creationism would be true in the realm of the inner self (spirit, soul) of the humanity (Chung, 2012).

Teilhard de Chardin describes in his book, "The Phenomenon of Man" the evolutionary process in humanity: First, creation of energy and fundamental particles of matter that correspond to the fire element of the Five Elements, next, geogenesis (earth element), metatlic barysphere (metal element) and hydrosphere (water element) in Earth, biosphere (wood element), evolution of noosphere in man, and then the supreme state, the Omega Point. The noosphere of man described by Teihard seems to coincide with the humanity of incarnated spirit in man who possesses thinking mind. The Omega Point is the union of man with God, "God all in everyone" as called by Teilhard. Teilhard integrated geobiological phenomena in evolution of humanity with Christian theology. This coincides with Homo divina in the kingdom of God where goodness will be boundless as predicted in the

Table 3. The evolution of humanity: comparison of stage, time of emergence in evolution and corresponding human (self) based on the ultron-logotron theory (Chung, 2014a, 2014b).

\begin{tabular}{cccc} 
Stage & Humanity & Time $^{\mathrm{a}}$ & Self \\
\hline First & Homo $^{\mathrm{b}}$ (genus) & $2.3-1.5$ million BP & The physical self/body \\
Second & Homo sapiens (species) & $200,000 \mathrm{BP}$ & The physical self/body \\
Third & Homo sapiens sapiens ${ }^{\mathrm{c}}$ (subspecies) & $120,000 \mathrm{BP}$ & The physical self/body and the inner self \\
Fourth & Homo divina $^{\mathrm{d}}$ & $5000 \mathrm{BP}$ & The physical self/body and the super self \\
\hline
\end{tabular}

${ }^{\mathrm{a}}$ Time is estimated based on reports in anthropology (Joseph, 2011a, 2011b; Wikipedia, 2014a-2014d, 2014f, 2014g).

${ }^{\mathrm{b}}$ Homo habilis, Homo ergaster, Homo erectus, Homo heidelbergensis, Homo denisova and Homo neanderthalensis, predecessor to Homo sapens are included (Wikipedia, 2014g).

${ }^{\mathrm{c}}$ The earliest transmigration (incarnation) of human spirit entities (the inner self) in Homo sapiens and then modern humans, Homo sapiens sapiens emerged. This evolution is postulated to have taken place 120,000 BP (see text).

${ }^{\mathrm{d}}$ Divine man will continue to come to Earth in the future evolution (see text). 
Bible and Jeong Yeok, and the East and the West will unite (Chung, 2009, 2010).

Lehman and Persinger (2015) have published their article, "Convergent quantification and physical support for Teilhard de Chardin's philosophy concerning the human species and evolutionary consciousness”. Persinger and his group (Lehman \& Persinger, 2015; Dotta \& Persinger, 2012a) applied quantification from contemporary physics, the environmental sciences and quantum concepts to Teilhard de Chardin's philosophy. There seem to be a considerable agreement between the Ultron-Logotron theory (Chung, 2015a) and Teilhard de Chardin's philosophy or the report of Lehman and Persinger (2015) concerning the evolution of humanity.

Further research would be needed for verification of the above hypothesis regarding the evolution of humanity proposed from the perspective of the author's ultron-logotron theory.

\subsection{Parallels between Confucian Philosophy and Quantum Physics}

Results of the study based on the ultron-logotron theory, review of quantum physics and Confucian philosophy reveal remarkable parallels between Confucian philosophy and quantum physics as follows:

1) Confucian philosophy presents the "ultron" as the building blocks of the physical world, and the ultron-logotron theory proposes the "logotron" as the building blocks of the consciousness world at quantum levels.

2) There seem to be remarkable parallels between Confucian philosophy of the Eastern philosophy and quantum physics of the Western science from the ontological perspective.

3) There could be primary basic elementary particles, yin- and yang-“ultron" in the deeper structure of quarks and electrons.

4) Results of the study may suggest existence of eight flavors of quarks and there would be possible two more undiscovered flavors of quarks.

5) The physical world, the consciousness world and the spiritual world of our universe coexist in superposition and represent the macro-cosmos of the Creator God. The superpositioned worlds, the macro-cosmos of the Creator of our universe, the Self, seem to be analogous to the physical body, the conscious mind and the inner spiritual self in superposition that represent the micro-cosmos of the co-creator, the self of the humanity.

6) The spiritual world is invisible but real. The spiritual world and the human world would unite in the coming kingdom of heaven on Earth where goodness will be boundless according to Jeong Yeok, the Book of Right Change of Confucian philosophy as the Bible predicts it.

7) Virtual particles are in essence virtual logotrons (information) that are the archetype of real particles. Annihilation and creation of ultrons (matter) are secondary to action of underlying virtual logotrons in the Cosmic Consciousness (mind). This seems to suggest that the ultron-logotron theory possibly leads to the Theory of Everything (ToE).

Further research would be needed for verification of parallel relationships between Confucian philosophy and quantum physics.

\subsection{The Theory of the Five Elements}

The Theory of the Five Elements is described not only in Confucian philosophy (William, 1967; Kim, 1885; Chung, 2014b; DSJR, 2013) but also Hinduism (Yogananda, 1957) and Buddhism (Dalai Lama, 1992).

The principle of the Five Elements is defined as a principle of cosmic creation in the Eastern philosophy. The five elements in Confucian philosophy are earth, metal, water, wood and fire (Figure 2).

According to Yogananda (1957), the universe is made of the five elements, that is, earth, air, water, fire, and ether. These elements mutually support, check and balance. These elements compose human bodies.

The star-like shape of the human body represents the five elements: the head, two arms and two legs. The hand is composed of five fingers. The thumb represents the earth element. The index finger represents the water element. The middle finger represents the fire element. The ring finger represents the air element. The little finger represents the ether element. The air and ether elements in Hinduism are inferred to be analogous to the metal and wood elements in Confucian philosophy. The five elements are thought to be five vibratory creative energies.

\subsection{Traditional Chinese Medicine (TCM)}

Acupuncture of the traditional Chinese medicine (TCM) has been widely practiced in alternative medicine for 


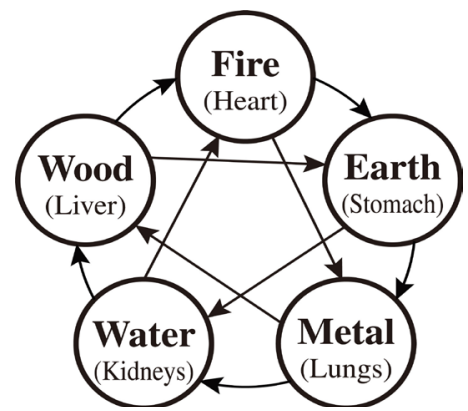

Figure 2. Diagram of the five elements. Arrows indicate interaction between each of the five elements (organs): fire (heart), earth (stomach), metal (lungs), water (kidneys), and wood (liver). The outer clockwise arrows show a cycle of support. The inner arrows show regulation of target organs by corresponding organs. The five elements (organs) mutually interact (see text).

thousand years in China and the Eastern countries (Liao, 1994; Gerber, 2001; Burton Goldberg Group, 1993; Jang, 2009).

Professor Bong Han Kim, MD (1963, 1965), Korea, was the first in the history of traditional medicine to prove the Bonghan ducts (BHD) and corpuscles (BHC) that correspond to the paths of acupuncture meridians with his extensive scientific researches. BHC corresponds to the acupuncture points (AP) and BHD corresponds to the meridians (AM). The Bonghan duct system (BDS) is a newly discovered, third circulatory system (Bonghan circulatory system, BHCS) in addition to blood and lymph systems (Soh, 2009; Gerber, 2001; Avijgan \& Avijgan, 2013).

Only recently, Professor Kwang-Sup Soh and his coworkers (Soh, 2004, 2009, 2015; Lee et al., 2007, 2009) at Seoul National University, clearly confirmed the existence of Bonghan circulatory system (Primo Vascular System, PVS) composed of Bonghan ducts (primo vessels, PV) and corpuscles (primo nodes, PN) that correspond to the paths of traditional acupuncture meridians, by employing their modern updated technology and BHCS-specific dye, Trypan blue. The system is located on the surface of internal organs, in the brain, within the blood and lymph vessels as well as in the skin of the whole body. BHD/BHC is present in six categories as follows:

1) Superficial BHC/BHD located in the skin.

2) Intravascular BHC/BHD along the interior of the large veins, arteries and lymph vessels, afloat and not adhering to the vessel wall.

3) Extravascular BHC/BHD along the exterior of large blood vessels.

4) Organ-surface BHC/BHD on various internal organ-surfaces.

5) Intra-organ BHC/BHD located inside various internal organs.

6) Neural BHC/BHD inside the brain and spinal cord and along the exterior of peripheral nerves.

Bonghan circulatory system, BHCS, (PVS) composed of BHCs (PN) and BHDs (PV) forms a web-like network (Figure 3) in the body of not only humans but also vertebrates (Kim, 1963; Soh, 2009; Lee et al., 2009; Avijgan \& Avijgan, 2013).

Bonghan liquor flowing in BHD/BHC contains a large amount of nucleic acid, DNA and RNA that are hitherto considered to exist in the nucleus and in the nucleus and cytoplasm of cells, respectively. They are really outside of the nucleus, and freely circulate in the BHD. The speed of flow is $0.3 \mathrm{~mm} \pm 0.1 \mathrm{~mm} / \mathrm{sec}$.

There are very small granules, microcells (originally called "sanal”) in BHD/BHC that contain amino acid, neurotransmitter, adrenalin and noradrenalin, hyaluronic acid and some other substances vital for cells and tissues as well as one or two chromosomes (Avijgan \& Avijgan, 2013; Soh, 2009).

Immune cells, monocytes, mast cells, macrophages and eosinophils are present in BHC/BHD. Stem cells are found in BHC, suggesting that Bonghan microcells have a function of hematopoietic organ (Soh, 2009; Baik et al., 2009; Avijgan \& Avijgan, 2013). Bonghan circulatory system (BHCS, PVS) may have a great significance in relation to serious health problems in modern society such as obesity and cancer (Soh, 2009, 2015).

\section{7. Healthy Lifestyles}

Andrew Weil (1995a) published in his book, Natural Health, Natural Medicine, five healthy lifestyles: how to eat, 

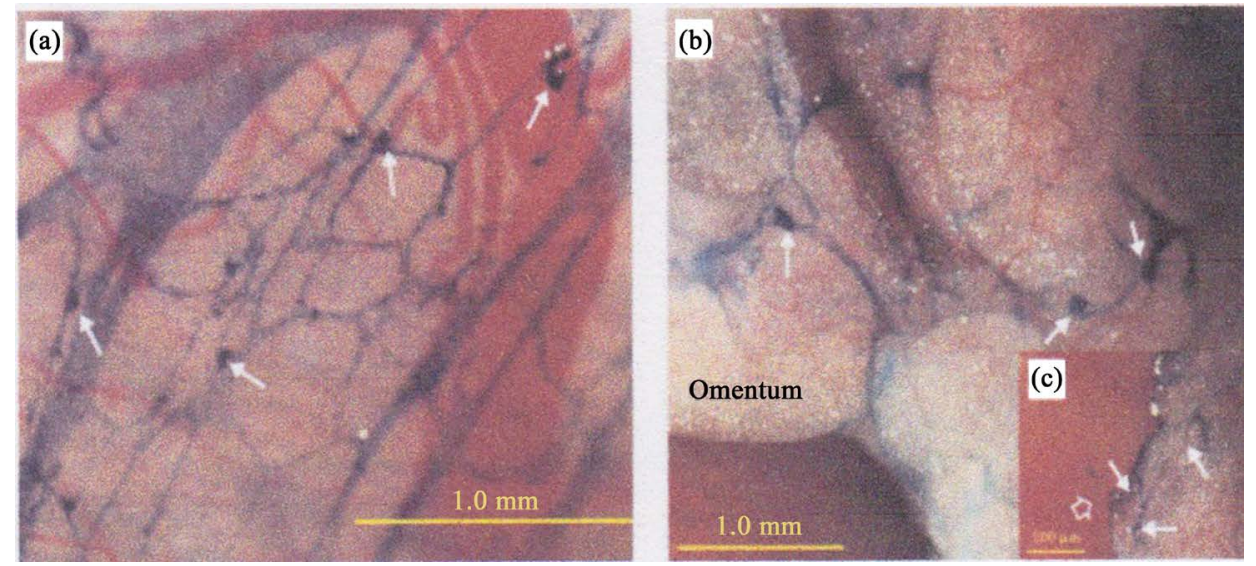

Figure 3. Weblike network of BHDs revealed by using Trypan blue. (a) The web of BHDs on the visceral peritoneum around the stomach near the spleen of a rat. There were several small BHCs at crossing points, as indicated by the arrows. The blood capillaries were not stained. (b) The network of BHDs on the omentum below the stomach and over the small intestine. Three small corpuscles at the crossing points of BHDs are indicated by the arrows. (c) In the inset another part of the same omentum as in (a) is shown. Here, the floating BHD (open arrow) was connected to the BHDs (arrows) in the omentum. This figure shows that the BHDs on the omentum was a part of the larger network of freely movable BHDs on the surfaces of internal organs which were previously reported (Shin et al., 2005; Lee et al., 2007).

how to drink, proper breathing, exercise, and relaxation for optimum health and prevention of disease. He presented a complete guide to health and prevention of disease as preventive medicine that he called "natural therapies" and "natural medicine".

The Theory of the Five Elements described in Confucian philosophy seems to be a fundamental and comprehensive principle, involving the universe as well as humanity in cosmology, evolution, biology and medicine. However, the relationship between the Five Elements and science are not explained in physics, biology and medicine (Chung, 2014b).

Possible scientific relationships between the Theory of the Five Elements of the Eastern philosophy and science of cosmology, evolution, biology and medicine are investigated in this study, and an attempt is made to find objective proofs and scientific evidence that would elucidate the relationship, and further to confirm that the principle of the Five Elements may be a scientific principle of universal creation (a law of nature).

\section{Results}

\subsection{Cosmology and Evolution}

Subatomic fundamental elements, ultimate units, ultrons of matter were created in a Big Bang. This event is described as "original heavenly fire" in Jeong Yeok in cosmogenesis (Kim, 1885; Yi, 1992; Chung, 2010). Hydrogen and helium generated from subatomic fundamental elements in the Big Bang produced stars. In the course of contraction and cooling of the sun, the planet, Earth was created. Stars and the Earth represent the earth element of the Five Elements. In these processes, the fire generated the earth element.

Hydrogen and helium created other atoms, carbon, oxygen and iron etc. in the hot sun. Metal iron in the core, and oxygen in the crust and the atmosphere of Earth resulted in the course of cooling of Earth. This process represents that the earth element (hydrogen) generates metal element (iron). Oceans on the surface of Earth and ground water were then produced from the combination of hydrogen and oxygen emitted from the rocks of the crust of Earth in the course of cooling. This process represents that the metal element created the water element.

In water of oceans, primitive forms of life developed possibly from chance combinations of atoms into large inorganic, organic, self-reproducing molecules, further, cells, fish, and evolved to insects, birds, reptiles, mammals, primates, and ultimately human race (Darwin, 1859; Teilhard de Chardin, 2008; Lockley, 2011; Sadava et al., 2011). This process of biogenesis and anthropogenesis corresponds to the Theory of the Five Elements: the water generates the wood element (the tree of life called by Teilhard de Chardin, 2008).

The above described processes of cosmic creation and evolution of humanity seem to suggest that the Theory of the Five Elements 五行 of the Eastern philosophy might be valid in the cosmic creation, cosmogenesis and 
evolution of humanity. These processes might be expressed as follows (Figure 2):

Energy and ultrons $\rightarrow \mathrm{H}$ (hydrogen) $\rightarrow \mathrm{O}$ (oxygen) $\rightarrow \mathrm{H}_{2} \mathrm{O} \rightarrow \mathrm{C}, \mathrm{H}, \mathrm{O}, \mathrm{N}, \mathrm{P}, \mathrm{S}^{*}$

fire $\rightarrow$ earth $\rightarrow$ metal $\rightarrow$ water $\rightarrow$ wood

*Carbon, hydrogen, oxygen, nitrogen, phosphorus, and sulfur are major elements of our bodies.

\subsection{Human Embryology}

In the first month of human pregnancy, heart tube (an organ of transport and supply of nutrients and oxygen) forms and begins to pulsate and force blood to circulate through blood vessels in embryonic discs (Steding, 2009; Child Development Institute, 2009). This is symbolized by fire of the Five Elements, corresponding to the "original heavenly fire" described in Jeong Yeok. This represents the first process of development of heart of the internal organs.

Development of other internal organs begins. The foregut (stomach and proximal portion of intestine, an organ of digestion and absorption of food) emerges from the endoderm in week 3 after the heart (Child Development Institute, 2009). This step corresponds to that the fire element generates the earth element.

The respiratory bud of lung (an organ of breathing of oxygen and carbon dioxide) develops from the ventral wall of the foregut probably in early week 4 (Wikipedia, 2015a), indicating that the earth element generates the metal element that symbolizes the lung as explained before in Introduction.

Development of kidneys (an organ of water metabolism and excretion of wastes) as the urogenital ridge arises from intermediate mesoderm in week 4 (Wikipedia, 2015c, 2015d).

The liver (an organ of metabolism of nutrients, production of vital substances and excretion of wastes) develops from the ventral portion of the foregut endoderm (Rana, 1998; FitzGerald \& FitzGerald, 1994). Development of the glandular epithelium (endoderm) is induced by the surrounding mesoderm, which is specific to each particular gland (Rana, 1998; FitzGerald \& FitzGerald, 1994). Development of liver follows that of kidney in week 4 (Rana, 1998; Steding, 2009; FitzGerald \& FitzGerald, 1994). Development of liver from endoderm seems to be after development of the foregut (stomach), lungs from foregut and kidneys from mesoderm (Wikipedia, 2015b; Rana, 1998; Steding, 2009). Liver as a symbol implies the wood element (the tree of life) as before mentioned.

The liver has a wide range of functions in the human body. The development of the liver takes from week 4 up to week 8 in human embryogenesis, arising from the endoderm (Wikipedia, 2015b; Rana, 1998; FitzGerald \& FitzGerald, 1994).

Development of other organs of the nervous, endocrine, muscular and skeletal systems etc. are not included in this study.

The above findings and results in the visceral organogenesis seem to suggest that the approximate timetable of development of the internal organs, heart, stomach, lungs, kidneys and liver correspond to the order of fire, earth, metal, water, and wood of the Five Elements in their generation (Figure 2).

\subsection{Bonghan Circulatory System and Acupuncture}

Acupuncture alleviates pain and can increase immune response by balancing flow of vital fluid containing nucleic acids and other substances throughout the body (Kim, 1963; Han, 2004; Soh, 2009, Gerber, 2001, Burton Goldberg Group, 1993; Avijgan \& Avijgan, 2013).

The World Health Organization has cited 104 different conditions that acupuncture has treated, including migraine, asthma, sinusitis, sciatica, osteoarthritis, stroke and speech aphasia (Burton Goldberg Group, 1993). Acupuncture has proven to be a successful treatment for pain relief (Burton Goldberg Group, 1993; Han, 2004; Thomas et al., 2006; Eisenberg \& Wright, 1987; Millman, 1977; Cheung, 1985).

Acupuncture has been proven to be a successful treatment for pain relief (Burton Goldberg Group, 1993; Han, 2004; Thomas et al., 2006; Eisenberg \& Wright, 1987; Millman, 1977; Cheung, 1985). Acupressure is same as acupuncture, using hands instead of needles (Gach, 1990; Kolster \& Waskowiak, 2007).

$\mathrm{BHC} / \mathrm{BHD}$ contains immune cells and stem cells, and is a hematopoietic organ. Kim reported that granules and microcells of BHC/BHD have an important role in regeneration of damaged liver cells. BHC/BHD is involved in regeneration of damaged cells, tissues and organs (Soh, 2009; Avijgan \& Avijgan, 2013). BHC is an excitable organ by mechanical, electrical and other stimuli.

The content of BHC/BHD is entirely different from those of blood and lymph. BHC/BHD contains a large 
amount of DNA that is hitherto considered to exist in the nucleus, surprisingly being outside the nucleus and flowing in the BHC/BHD.

BHC/BHD seems to be analogous to neurons of brain and a hematopoietic organ of bone marrow as well as an embryonic adult stem cell on the basis of its biological functions. DNA in BHD/BHD may open unexpectedly feasible stem cell therapy in medicine (Kim, 1963; Soh, 2009; Baik et al., 2009).

Results of biomedical research conducted in the traditional medicine strongly suggest that internal organs are interconnected with a web-like network of BHC/BHD, and are closely interrelated and mutually support, coordinate and involved in replication, regeneration and restoration. These findings and discoveries are most likely indicate that internal organs, heart, stomach, lungs, kidneys and liver that correspond to the five elements interrelate, support, coordinate, and regulate each other.

Richard Gerber (2001) describes in his book, Vibrational Medicine that the heart, lung, liver and kidney interact, check and balance each other, and restore health as similarly suggested by the Theory of the Five Elements.

Figure 2 illustrates the relationship between each of the internal organs, the direction of flow of substances, energy and effects. The diagram seems to correspond to the Bonghan Circulatory System (PVS), and the cycles of support (generation) and regulation (control) described in traditional Chinese medicine are included. The author infers that the diagram shown in Figure 2 is a representative illustration of the relationship between each of the internal organs described in traditional medicine.

\subsection{Five Healthy Lifestyles}

\subsubsection{Food and Diet}

The healthy diet has been advocated over the last few decades. The desirable diet food includes vegetables, legumes, fruits, vitamins, minerals and seafood (Weil, 1995a, 1995b, 2001; Wu, 2014; The University of California, Berkeley, 1991).

Limitation of fat intake, adequate calories and protein intake, prevention of obesity, maintenance of adequate weight etc. are widely recommended for optimum health and prevention of disease.

Wu (2014) recommends vegetarian diet for not only individuals but also the entire globe, explaining health benefits and global benefits.

Food represents the earth element of the Five Elements. Food contains important substances composing our body. Good food is required for optimum health.

\subsubsection{Breathing}

"Proper breathing (of clean air) is the most effective lifestyle to oxygenate our body properly as well as correcting all internal and energetic balance, and it has a direct impact to our nervous system” (Weil \& Kabat-Zinn, 2001; Weil, 1995a, 2001). Practice of slow, deep, quiet, and regular breathing every day that is recommended by Andrew Weil, M.D. (1995a) is desirable for optimum health. Yoga breathing is considered to have same effects on health.

Oxygen is the most abundant element in the crust of Earth and the atmosphere (next to nitrogen). In the geogenesis, heavy iron descended into the core of Earth and light oxygen ascended into its crust, then emitting oxygen into the atmosphere. In this process, the iron metal in the core implies the oxygen in the air as well as the lungs of the body. The iron atom present in molecules of hemoglobin in red blood cells play a physiological roll in binding, transporting and releasing oxygen between the lungs (air) and tissues. The metal element represents the lungs in the traditional medicine, and air in Hinduism in the Theory of the Five Elements.

The heart practically does not get primary cancer. Cancer grows in anaerobic environment. It does not survive in high concentration of oxygen (Warburg, 2015).

Iron element has therefore an important connection to the desirable lifestyle of proper breathing, implying that the metal element of the Five Elements supports health of human beings. Breath gives life energy. Human inner self (spirit) lives in the physical body during a period from the first breath after birth to the last breath at death (Genesis 2:7; Weil, 1995a).

\subsubsection{Water}

Water makes up about $70 \%$ of the weight of our body. Water maintains proper functions of all cells. Water is needed for breakdown, absorption, transportation and supply of nutrients, energy and oxygen for all tissues and 
organs. Water increases the efficiency of the immune system, including efficiency against cancer. Water clears toxic wastes from different parts of the body and transports them to the liver and the kidneys for disposal (Weil, 1995a; Batmanghelidj, 2003; Ju, 2014). Sufficient water flowing through the kidneys is required for the kidneys to purify blood and control the normal composition of blood.

The proper amount of drinking good-quality water every day depends on the amount of water contained in food, lost water through urine, lungs, feces and skin. It is estimated about 1.7 liter (Ju, 2014), or six to eight glasses of water daily (Weil, 1995a). Heart has practically no cancer, most likely due to rich supply of oxygen in circulating blood composed of about 90\% of water (West \& Todd, 1961; McManus \& Davis, 1996).

Adequate daily intake of water is desirable for optimum health, implying that the water element supports health.

\subsubsection{Exercise}

Exercise is one of the most important life styles for optimum health and prevention of disease. Aerobic exercise decreases risk factors of heart disease, hypertension and incidence of type 2 diabetes, increases brain functions, and prevents Alzheimer's disease and mental cognitive impairment (Weil, 1995a; Baker, 2015; Sigal et al., 2006). Weil (1995a) recommends moderate exercise of 30 minutes of aerobic exercise at least five days a week.

Aerobic exercises elicit movements of muscles, bones and joints, and increases blood flow in all parts, particularly internal organs and brain (Baker, 2015; Ju, 2014). Exercise strengthens the bone and helps prevent osteoporosis. Exercise is widely recommended for health.

In the evolution, quadriped animals evolved to biped Homo sapiens, freeing hands of man that made man be able to create human civilization, agriculture, industry, technology, science, arts, sports etc (Kinney, 1998). This reveals that man with free movements of hands, arms, and legs of the body could have created civilization as well as being healthy. Exercise is assumed to represent the wood element of the Five Elements, the tree of life, benefiting human beings. Heart practically does not get cancer probably due to its continuous beat and blood circulation (Ju, 2014).

\subsubsection{Relaxation}

Prayer and meditation that help relaxation are recommended for optimum health and prevention of disease (Weil, 1995; Benson, 1996; Block, 2009). Herbert Benson, M.D. at Harvard Medical School (1960s) found that meditation lowered metabolic rate, blood pressure and levels of blood lactate of meditators. Extensive researches on mind/body influences have been since begun (Davidson, 2016).

OM chant is recommended in spiritual meditation in Hinduism and Confucianism (Yogananda, 2004; Chung, 2010). Om sound is said to represent the divine sound of the cosmos. Chanting OM is helpful during relaxation practice (Benson, 1996).

Relaxation is assumed to represent the fire element of the Five Elements. The lifestyle of relaxation is for the inner/super self (the true self, spirit) and the other lifestyles, good food, breathing, water and exercise are primarily for the physical self/body from the perspective of the author's ultron-logotron theory (Chung, 2012, 2014b, 2015a, 2015b).

Good food containing proteins, lipids, carbohydrates, vitamins and minerals of the earth element, and oxygen in breathing of the metal element, and water of the water element are indispensable compounds to keep optimum health and prevention of diseases, suggesting that the principle of the Five Elements of the above three elements together with the exercise of the wood element and the relaxation of the fire element be the principle of creation of life and health in medicine.

\section{Discussion}

In cosmogenesis, subatomic fundamental elements, ultimate units, ultrons and atoms of hydrogen were created in a Big Bang, corresponding to the "original heavenly fire" described in Jeong Yeok, then stars and the planet, Earth were generated, corresponding to that the fire element generated the earth element of the Five Elements. Heavy metal iron descended into the core of Earth and light oxygen ascended into the crust of Earth, corresponding that the earth element generated the metal element. Hydrogen and oxygen combined and generated oceans on Earth, corresponding to that the metal element generated the water element. Living organisms were formed in the ocean, corresponding to that the water element generated the wood element. 
Results of this study seem to reveal that the Theory of the Five Elements is the principle of cosmic creation and evolution in cosmogenesis, geogenesis, biogenesis and anthropogenesis.

An approximate timetable of development of the internal organs, heart, stomach, lungs, kidneys and liver seems to correspond to the order of the Five Elements: fire generates earth, earth generates metal, metal generates water, and water generates wood (Figure 2) (Rana, 1998; FitzGerald \& FitzGerald, 1994; Steding, 2009; Wikipedia, 2015a, 2015b, 2015c).

Acupuncture of the traditional Chinese medicine is widely used as a successful treatment of pain relief (Han, 2004; Burton Goldberg Group, 1993; Cheung, 1985). The Bonghan Circulatory System (Primo Vascular System) is a network composed of Bonghan ducts (Primo Vessels) and Bonghan corpuscles (Primo Nodes) along the paths of acupuncture meridians. It is only recently confirmed to be a new third circulatory system besides the blood and lymph systems, and further a hitherto-not-clearly-known third regulatory system different from the nervous and endocrine systems (Kim, 1963; Soh, 2009; Avijgan \& Avijgan, 2013; Solomon, Berg, \& Martin, 2006).

Subductules exist within the ducts. Floating granules containing nucleic acids with genetic information and other substances vital for cells and tissues circulate through the ductules. Bonghan microcells (PMC) containing adult stem cells may be successfully directed to target damaged tissues and organs for stem cell therapy (Kim, 1963; Solomon et al., 2006; Soh, 2009).

DNA granules can be excited by any stimuli, resulting in a long-range electromagnetic waves and fields, and emit photons, being a source of biophotons, excitons, that would be transmitted along BHC/BHD, and produce biomedical responses in connected internal organs including the brain (Avijgan \& Avijgan, 2013). Emissions of photons have been detected from the liver, heart, lung, muscles and human skin (Avijgan \& Avijgan, 2013). DNA included in BHC (PMC) that is the store and source of biophotons suggests that biophotons (being Qi called in traditional medicine) could be produced by various stimuli used in acupuncture and directed to any desirable target organs for treatment (Soh, 2004; Avijgan \& Avijgan, 2013).

If a clear map of the PVS (BHCS) network showing relationships among all parts of the body including the five organs of the Five Elements as well as the cycles of support and regulation is developed, Qi (biophotons) could be directed to target organs for treatment in acupuncture (Avijgan \& Avijgan, 2013). Soh (2015) has recently proposed a hypothesis on cancer treatment: "Injecting anticancer drugs into acupoints according to the pharmacopuncture method can be effective as a result of the flow channels of the PVS, the acupoint Zusanli (ST 36) and the route of the primo vessels starting from it and running along the specific PVS paths, the sciatic nerve, spinal cord to the brain. Thus, one can deliver the drug into the brain to treat gliomas and other brain tumors, avoiding the blood-brain barrier. This new drug-delivery method is just one of the new clinical applications that are possibly by combining acupuncture and using the PVS, and may be useful in the field of oncology”.

This inter-cellular communication with biophotons in the network of Primo Vascular System (BHCS) seems to explain therapeutic effects of acupuncture (Soh, 2004; Avijgan \& Avijgan, 2013).

Figure 2 illustrates interrelations between each of the five elements described in the Five Elements. The support and generation of earth element by fire element, metal element by earth element, water element by metal element and wood element by water element described in the eastern traditional medicine is shown with the outer arrows in Figure 2 and explained as follows:

1) The heart representing the cardiovascular system (fire element) transports materials, nutrients, oxygen, and other vital compounds to all tissues and organs including stomach (earth element), and wastes and toxins to the kidney and liver for excretion.

2) The stomach representing the gastrointestinal system (earth element) digest and absorb food and supply nutrients to all tissues and organs including the lungs, metal element, after liver passage.

3) The lungs (metal element) supply oxygen to all tissues and organs including the kidneys, and excrete carbon dioxide.

4) The kidneys (water element) regulate composition and contents of blood, regulate blood chemistry, excrete wastes, and produce hormones, erythropoietin and renin, supporting organs including the liver, wood element.

5) The liver (wood element) metabolizes and produces nutrients and detoxifies toxins and excretes wastes through bile, supporting organs including the heart, fire element.

The regulation and control of fire element by water element, metal element by fire element, wood element by metal element, earth element by wood and water element by earth element are also shown with the inner arrows in Figure 2. 
The kidneys (water element) as one of the body's self-healing systems regulate and control the composition of blood circulating through the cardiovascular system (fire element) by filtering the blood. The kidneys with heart and blood as a single functional unit constantly cleanse, purify itself, and keep blood acid-base and electrolytes balances, and blood volume, removing toxic wastes of metabolism and harmful substances that get into the body (Weil, 1995a; Kaplan et al., 2003). Renin hormone produced in the kidneys and other hormones by the endocrine system are involved in the function of the kidneys. This process seems to indicate that the water element of kidney regulates and controls the fire element of heart (Figure 2) and it is analogous to that water extinguishes fire.

The function of heart is connected with the lungs via the involuntary autonomic nervous system and the endocrine system. Anger and fear may cause rapid heartbeat and increased blood pressure, then simultaneously rapid, shallow and irregular breathing; and left-sided congestive heart failure results in pulmonary congestion, edema, and dyspnea (breathlessness) (Weil, 1995a; Cotran et al., 1999), seemingly indicating that the heart, fire element regulates and controls the lung, metal element.

Oxygen molecules that enter the liver cells would be utilized in oxidation of foods absorbed from the gastrointestinal tract, and production of high-energy adenosine triphosphate (ATP) compounds. ATP is involved in various chemical reactions in metabolism of nutrients by releasing free energy (West \& Todd, 1961). Oxygen symbolizes the lungs, suggesting that the lungs, metal element regulates and controls the liver, wood element.

The liver produces glucose from absorbed food. The function of the stomach depends on glucose and oxygen in blood. The liver also detoxifies toxic foreign substances absorbed from the gastrointestinal tract. In this sense, the liver, wood element regulates and controls the function of the stomach, earth element.

Water is absorbed from the gastrointestinal tract. The water volume in blood is regulated by the kidneys, seemingly suggesting that the stomach (earth element) regulates and controls the function of kidneys (water element). It is analogous to that the banks and dams of earth regulate and control flow of water.

The five internal organs, heart, stomach, lungs, kidneys and liver work together, mutually interact, support, regulate, control, restore, regenerate, and function directly or indirectly through the cardiovascular and lymph systems, the nervous system, the endocrine system, and most likely the primo vascular system (BHCS), with negative feedback in homeostasis to maintain normal compositions and contents of body fluids for optimum health and support of life, suggesting that the principle of the Five Elements reflects an underlying principle of the pathophysiology of the human body (Figure 2) (McCance \& Huether, 2014).

It is taught in religions that the universe is filled with omnipresent God's love (Yogananda, 2004; Chung, 2014b). God's love is conjectured to be life energy (word: logotron of the Cosmic Consciousness) and manifested presumably through the Primo Vascular System (PVS) (as one of various unknown ways) for man by activating the channel of PVS (PVS acting an excitable organ like neurons) (Teilhard de Chardin, 2008; Lehman and Persinger, 2015). Our Creator God is giving life and health to humans as the sun is giving light energy to all living beings. Jesus said, "It is written, Man shall not live by bread alone, but every word that proceedeth out of the mouth of God.” (Matthew 4:4; Deuteronomy 8:3). This postulated invisible fact could be understandable as follows:

When a co-creator, a human being wants to move his hand, his conscious mind creates logotrons of 'moving his hand' in neurons of his brain that would result in movement of his hand by transmitting electrical impulses through involved peripheral nerves to hand muscles.

Lehman and Persinger (2015) have proposed that "spiritual energies" described by Teilhard de Chardin that seem to correspond to logotrons, building blocks of conscious mind, are mathematically quantifiable to values in magnitude to those that operate within quantum levels and presented mathematical convergent quantification and physical support for Teilhard de Chardin's philosophy concerning the human species and evolutionary consciousness (Persinger, 2013).

Conscious mind of the self (the inner true self) has inherent power to change logotrons from the ground state to the excited state with free will and free choice. Mentalons emitted from logotrons may convert the logotrons to entangled photons in cell membranes of neurons of human brain through the primordial electron spin-mediated process in non-spatial, non-temporal pre-space-time domain of Consciousness World (Spiritual World outside of the physical space-time) to which consciousness is inherently connected in quantum entanglement as described by $\mathrm{Hu}$ and $\mathrm{Wu}$ (2006). Logotrons of consciousness in the ground state or excited state seem to be in superposition to the status of electron spin in nonlocal and timeless world of quantum entanglement. Entangled photons arising in unpaired electron spin networks of the "mind screen" constitute "mind pixels" that seem to correspond 
to logotrons. Generation of photons from human brains by cognition, particularly visual imagination of white light (thought) coupled with photon emissions is experimentally confirmed by Dotta and Persinger (2011a), Dotta et al. (2012b). The energy of photon emission caused by imagination of white light (conscious concept) is within the range of about $10^{-12}$ Watts (Joules per second) per meter squared. This study seems to supports the electron-spin-mediated hypothesis of $\mathrm{Hu}$ and $\mathrm{Wu}$ for the origin of consciousness. Dotta and Persinger include detailed physical and mathematical analysis at quantum levels in their study (Dotta \& Persinger, 2011a, Dotta et al., 2011b, 2012b).

Spin of electrons was described as the zitterbewegung in Dirac equation (1928) and as quantum spin in Schrödinger equation (1935), and if the primordial electron spin-mediated consciousness truly exists, quantum computation of microcomputer proposed by Penrose and Hameroff (2011) would be possibly explained on the basis of coherence as unpaired spin state and decoherence as paired spin state. Logotrons and mentalons are not experimentally observed but their existences are understood by their effects and their self-awareness in the self's mind. There seems to be a considerable agreement and support between the ultron-logotron theory and the primordial electron spin-mediated consciousness theory of $\mathrm{Hu}$ and $\mathrm{Wu}$ for the origin of consciousness or the studies of Persinger and his group regarding the mind-matter relation.

The mentalon is the mediatory force at the mind-matter boundary, that is, at the interface between the prespatial (nonlocal) and pre-temporal (timeless) consciousness world (the spiritual world) and the space-time physical world. Mentalon is qualitatively different from photon but once converted into photon in quantum entanglement, it becomes qualitatively same as the physical photon that would be created in the body with the mentalon. Both photons are qualitatively same but may be quantitatively different. Mentalon-derived photon energy may be very small compared to physically emitted photon at quantum levels. Mentalon is conjectured to have inherent power to act on and react to the geomagnetic field.

It seems to have been experimentally proven that all things of Earth are interconnected with the geomagnetic field (Lehman \& Persinger, 2015; Persinger, 2014; Dotta \& Persinger, 2012a; Karbowski et al., 2015). Transmission of the mentalon is instantaneous but transmission of the four physical forces is maximum speed of light (Chung, 2014a, 2015b).

The inner self can create energy to change logotrons in ground state to those in excited state. In addition, the inner self can choose a wanted logotron among multiple logotrons in the ground state in neurons in the prefrontal cortex with free will and free choice. The physical self has no free choice nor free will (Chung, 2014a). The inner self is analogous to a railway controller at a train station. "The controller controls the safe and planned, right running of trains and liaises with all areas of the railway system to ensure smooth running of trains" (Job Guide, 2015) as the inner self controls the physical self/body by interacting with the prefrontal cortex of the human brain. All things are created by the Creator God. Artists can create art products but art products cannot create artists. Consciousness of mind is created by the inner true self of human beings. The consciousness of mind and the brain of body are not the true self. The inner true self is independent from matter of brain and consciousness of mind. Logotrons of consciousness and ultrons of matter exist in superposition (Table 1 and Table 2).

The author published a general mathematical model of probacent-probability equation that calculates probabilities of safe survival of humans and other living organisms exposed to any adverse circumstances or conditions, overcoming the risk (Chung, 1960, 2013). In this study lifestyles for optimum health and prevention of disease are investigated.

Results of this study reveal that the five lifestyles, good food, breathing, water, exercise, and relaxation are desirable for optimum health and prevention of disease. The lifestyles cannot be achieved by pharmaceutical drugs or surgical procedures (Ju, 2014) but can be practiced by thoughts and wills of human minds. The desirable life styles are recommended in traditional Chinese medicine (Ricketts, 2015).

There seems to be a remarkable agreement between both of the lifestyles of Andrew Weil (1995a) and the current study regarding recommended lifestyles for optimum health and prevention of disease. The good lifestyles not only give optimum health but also happy lives and power of support and service to our families, societies and nations. In the future evolution of humanity, Homo sapiens sapiens, modern man would become divine man, Homo divina in the kingdom of God (Joseph, 2011b; John 10:34, 14: 10 - 14; I John 3:2; Kim, 1885; Chung, 2015a).

The Theory of "Five Elements" seems to be a scientific principle of creation in the universe (a law of nature) in creating all things, and giving life and health to the humanity like the Yin and Yang principle in Confucian philosophy, and further helping the humanity bring prosperity with unimaginable advancement in science, tech- 
nology and civilization to societies and nations (Kaku, 2008; Joseph, 2011b; Baik, 2015; Chung, 2013, 2015a).

Further scientific research would be needed for verification of the results presented in this study and the theory of the Five Elements.

\section{Conclusion}

On the basis of results of this study on relationships between the Theory of the Five Elements 五行 of the Eastern philosophy and science of cosmology, evolution, embryology, and traditional medicine, the following conclusion is proposed:

1) The principle of the Five Elements seems to be applicable to the cosmogenesis, geogenesis, biogenesis and anthropogenesis in cosmology and evolution of humanity.

2) The principle of the Five Elements seems to be likely applicable to the visceral organogenesis in human embryology in relation to the development of internal organs, heart, stomach, lungs, kidneys and liver.

3) Primo Vascular System (PVS) (Bonghan Circulatory System) is a newly-discovered, third circulatory system that corresponds to classical acupuncture meridians. The internal organs interconnected by a web-like network of PVS, mutually support, regulate, coordinate, control, and restore, suggesting that the principle of the Theory of the Five Elements seems to be applicable to Primo Vascular System. PVS is inferred to have a potentially important significance for health, and prevention and treatment of disease.

4) The principle of the Five Elements seems to be valid in medicine as well as alternative medicine.

5) The five lifestyles, good food, breathing, water intake, exercise and relaxation that correspond to the Five Elements seem to be desirable for optimum health and prevention of disease.

6) There seems to be a remarkable agreement between Teilhard de Chardin's philosophy supported by Lehman and Persinger (2015), and the ulron-logotron theory regarding the evolution of humanity.

7) There seems to be a considerable agreement and support between the ultron-logotron theory and the primordial electron spin-mediated theory of $\mathrm{Hu}$ and $\mathrm{Wu}$ for the origin of consciousness.

8) The theory of "Five Elements" seems to be a scientific principle of creation in the universe (a law of nature) in creating all things and giving life and health to humanity.

Further scientific research would be needed for verification of the theory of the Five Elements and the ultronlogotron theory.

\section{References}

Avijgan, M., \& Avijgan, M (2013). Can Prima Vascular System (Bong Han Duct System) Be a Basic Concept for Qi Production? International Journal of Integrative Medicine, 1, 1-10. http://cdn.intechopen.com/pdfs-wm/44168.pdf

Baik, K. Y., Ogaya, V., Jeungb, S. C., \& Soh, K. S. (2009). Visualization of Bonghan Microcells by Electron and Atomic Force Micrscopy. Journal of Acupuncture and Meridian System, 2, 124-129.

Baik, S. G. (2015). An Age Is Coming, Using a Holo Phone and Sleeping with a Robot. Monthly Chosun, 11, 369-376. (In Korean)

Baker, L. (2015). http://time.com/3968683/exercise-treatment-for-alzheimers

Batmanghelidj, F. (2003). Water: For Health, for Healing, for Life: You're Not Sick, You're Thirsty! New York: Warner Books.

Benson, H. (1996). Timeless Healing. New York: Bantam Book.

Block, K. I. (2009). Life over Cancer. New York: Bantum Book.

Bohm, D. (2006). Wholeness and the Implicate Order. New York: Rutledge.

Burton Goldberg Group (1993). Alternative Medicine. Puyallup, WA: Future Medicine Publishing, Inc.

Campbell, N. A., Reece, J. B., Mitchell, L. G., \& Taylor, M. R. (2003). Biology: Concepts and Connections (4th ed.). New York: Benjamin Cummings.

Capra, F. (1999). The Tao of Physics. Boston, MA: Shambhala.

Cheung, J. (1985). Effects of Electroacupuncture on Chronic Painful Conditions in General Medical Practice-A Four Year Study. American Journal of Chinese Medicine, 13, 33-38. http://dx.doi.org/10.1142/S0192415X85000071

Child Development Institute (2009). Approximate Timetable of Prenatal Development.

http://childdevelopmentinfo.com/chid-development/prenataldevelopment

Chung, S. J. (1960). Studies on a Mathematical Relationship between Stress and Response in Biological Phenomena. Repub- 
lic of Korea Journal of the National Academy of Sciences, 2, 115-162.

Chung, S. J. (2009). Seeking a New World: A New Philosophy of Confucius and Kim Hang. Bloomington, IN: iUniverse.

Chung, S. J. (2010). The Book of Right Change 正易: A New Philosophy of Asia. Bloomington, IN: iUniverse.

Chung, S. J. (2012). The Science of Self, Mind and Body. Open Journal of Philosophy, 2, 171-178. http://dx.doi.org/10.4236/ojpp.2012.23026

Chung, S. J. (2013). Mathematical Relationship of "Probacent”-Probability Equation among Exogenous Stressor, Stress and Response in Biological Phenomena. International Journal of Education and Research, 1, 1-32. http://www.ijern.com/September-2013.php

Chung, S. J. (2014a). Self and Consciousness: Mind and Matter. International Journal of Education and Research, 2, 1-28.

Chung, S. J. (2014b). Parallels between Confucian Philosophy and Quantum Physics. Open Journal of Philosophy, 4, 192206. http://dx.doi.org/10.4236/ojpp.2014.42027

Chung, S. J. (2015a). On the Evolution of Humanity: View from the "Ultron”-“Logotron” Theory. International Journal of Humanities and Social Science, 5, 50-63.

Chung, S. J. (2015b). On the Possible Deeper Structure of Leptons and Quarks. Open Journal of Philosophy, 5, 302-314. http://dx.doi.org/10.4236/ojpp.2015.55038

Close, F. (2011). The Infinite Puzzle. New York: Basic Books.

Cotran, R. S., Kumar, V., \& Collins, T. (1999). Robbins Pathologic Basis of Disease (6th ed.). Philadelphia, PA: W.B. Saunders Company.

Dalai Lama (1992). The Buddhist Concept of Nature. http://dalailama.com/messages/environment/buddhist-concept-of-nature

Darwin, C. (1859). On the Origin of Species. The Illustrated Edition, D. Quammen (2008). New York: Sterling Publishing Company.

Davidson, R. J. (2016). 3 Benefits of Mindfulness Practice for Your Brain. http://positivepsychologyprogram.com/benefits-of-mindfulness-practice

Dirac, P. A. M. (1928). The Quantum Theory of the Electron. Proceedings of Royal Society A, 117, 610-624. http://dx.doi.org/10.1098/rspa.1928.0023

Dotta, B. T., \& Persinger, M. A. (2011a). Increased Photon Emissions from the Right but Not the Left Hemisphere While Imagining White Light in the Dark: The Potential Connection between Consciousness and Cerebral Light. Journal of Consciousness Exploration \& Research, 2, 1463-1473.

Dotta, B. T., Buckner, C. A., Lafrenie, R. M., \& Persinger, M. A. (2011b). Photon Emissions from Human Brain and Cell Culture Exposed to Distally Rotating Magnetic Fields Shared by Separate Light-Stimulated Brains and Cells. Brain Research, 1388, 77-88. http://dx.doi.org/10.1016/j.brainres.2011.03.001

Dotta, B. T., \& Persinger, M. A. (2012a). Doubling of Local Photon Emissions When Two Simultaneous, Spatially Separated, Chemiluminescent Reactions Share the Same Magnetic Field Configuration. Journal of Biophysical Chemistry, 3, 72-80. http://dx.doi.org/10.4236/jbpc.2012.31009

Dotta, B. T., Saroka, K. S., \& Persinger, M. A. (2012b). Increased photon emission from the head while imagining light in the dark is correlated with changes in electroencephalographic power: Supprtt of Bókkon's biophoton hyposhtesis. Neuroscience Letters, 513, 151-154. http://dx.doi.org/10.1016/j.neulet.2012.02.021

DSJR (2013). The Principle of Creational Growth of All Things. http://www.dsjr.org/eng/edjg/text/edjg02.htm

Eisenberg, D., \& Wright, T. J. (1987). Encounter with Qi: Exploring Chinese Medicine (2nd ed.) New York: Penguin Books.

Enard, W., Preworski, M., Fishe, S. E., Lai, C. S., Wiebe, V., Kitano, T., Monaco, B. P., \& Paabo, S. (2002). Molecular Evolution of FOXP2, a Gene Involved in Speech and Language. Nature, 418, 869-872.

http://dx.doi.org/10.1038/nature01025

FitzGerald, M. J. T., \& FitzGerald, M. (1994). Human Embryology. Rochester, VT: Bailliere Tindall.

Freeman, S. (2008). Biological Science (3rd ed.). New York: Pearson.

Gach, M. R. (1990). Acupressure' Potent Points: A Guide to Self-Care for Common Ailments. New York: Bantam Books. Gerber, R. (2001). Vibrational Medicine. Rochester, VT: Bear \& Company.

Gisin, N. (2015). Quantum Chance: Nonlocality, Teleportation and Other Quantum Marvels. New York: Springer.

Griffiths, D. J. (2005). Introduction to Quantum Mechanics (2nd ed.). New York: Pearson Education, Inc.

Gross, D. R. (1992). Discovering Anthropology. Mountain View, CA: Mayfield Publishing Company.

Han, J. (2004). Acupuncture and Endorphins. Neuroscience Letters, 361, 258-261. 
http://dx.doi.org/10.1016/j.neulet.2003.12.019

Hawking, S. (1996). A Brief History of Time. New York: Bantam Books.

Hawking, S. (2001). The Illustrated a Brief History of Time. New York: Bantam Books.

Haywood, J. (1995). The Illustrated History of Early Man. New York: Smith Mark Publishers, Inc.

Howell, F. C. C. (1973). Early Man. New York: Time-Life Books.

Hu, H., \& Wu, M. (2006). Thinking outside the Box: The Essence and Implications of Quantum Entanglement and the Story of Spin-Mediated-Consciousness Theory. NeuroQuantology, No. 1, 5-16.

Jang, W. C. (2009). A Discussion on the Controversy of Relation between the Five Changes Theory and the Five Viscera from Geummun-Sangseo and Gomun Sangseo. Korean Journal of Medical Classics, 22, 61-70. (In Korean)

Janson, H. W. (1971). A Basic History of Art. New York: Abrahams Inc.

Jaybuck, E. J., \& Lutgens, F. K. (2003). Earth Science (10th ed.). Upper Saddle River, NJ: Pearson Education, Inc.

Job Guide (2015). Train and Network Controller.

http://www.jobguide.thegoodguides.com.au/occupation/Train-and-Network-Controller

Joseph, R. (2011a). Evolution of Paleolithic Cosmology and Special Consciousness and the Temporal and Frontal Lobes. In R. Penrose, S. Hameroff, \& S. Kak (Eds.), Consciousness and the Universe (pp. 631-682). Cambridge, MA: Cosmology Science Publishers.

Joseph, R. (2011b). Evidence of Consciousness in the Corner of the Cosmos. In R. Penrose, S. Hameroff, \& S. Kak (Eds.), Consciousness and the Universe (pp. 1026-1060). Cambridge, MA: Cosmology Science Publishers.

Ju, K. S. (2014). Water and Air and Health. https://player.vimeo/video/61628612

Kaku, M. (2008). Physics of the Impossible. New York: Anchor Books.

Kaplan, L. A., Pesce, A. J., \& Kazmierczak, S. C. (2003). Clinical Chemistry: Theory, Analysis, Correlation (4th ed.). St. Louis, Missouri, MO: Mosby

Karbowski, L. M., Murugan, N. J., \& Persinger, M. A. (2015). Experimentally-Induced Inhibition of Growth in Melanoma Cell Cultures Separated Two km When Both Share Excess Correlation Magnetic Fields: Macroscopic Evidence for Free-Space Quantum teleportation? Journal of Signal and Information Processing, 6, 39-48.

Kim, B. H. (1963). On the Kyungrak System. Journal of the Academy of Medical Science, DPK Korea, 90, 1-41.

Kim, B. H. (1965). Theory of Sanal. Journal of Jo Sun Medicine, 108, 69-104.

Kim, H. (1885). Jeong Yeok, 金恒, 正易, 정역. The Original Chinese Text with the Text Translated in Korean by Jeong Ho Yi (1990). Seoul: The Asian Culture Press.

Kinney, K. (1998). Ancient Civilizations. Richmond, VA: Time-Life Inc.

Kolster, B. C. \& Waskowiak, A. (2007). The Acupressure Atlas. Rochester, VT: Healing Arts Press.

Laszlo, E. (2008). Quantum Shift in the Global Brain. Rochester, VT: Inner Traditions.

Lee, B. C., Kim, K. W., \& Soh, K. S. (2009). Visualizing the Network of Bonghan Ducts in the Omentum and Peritoneum by Using Trypan Blue. Journal of Acupuncture and Meridian Studies, 2, 66-70. http://dx.doi.org/10.1016/S2005-2901(09)60017-0

Lee, B. C., Yoo, J. S., Ogay, V., Kim, K. W., Dobberstein, H., Soh, K. S., \& Chang, B. S. (2007). Electron Microscopic Study of Novel Threadlike Structures on the Surface of Mammalian Organs. Microscopic Research and Technique, 70, 34-43. http://dx.doi.org/10.1002/jemt.20383

Lehman, B., \& Persinger, M. A. (2015). Convergent Quantification and Physical Support for Teilhard de Chardin’s Philosophy Concerning the Human Species and Evolutionary Consciousness. Open Journal of Philosophy, 5, 338-350. http://dx.doi.org/10.4236/ojpp.2015.56042

Liao, S. J., Lee, M. H. H., \& Ng, L. K. Y. (1994). Principles and Practice of Contemporary Acupuncture. New York: Marcel Dekker, Inc.

Lockley, M. (2011). The Evolution of Human Consciousness Reflection on the Discovery of Mind and the Implications for Materialist Darwinism Paradigm. In R. Penrose, S. Hameroff, \& S. Kak (Eds.), Consciousness and the Universe (pp. 713-721). Cambridge, MA: Cosmology Science Publishers.

MacAndrew, A. (2004). FOXP2 and the Evolutionary Language. http://www.evolutionpages.com/FOXP2_language.htm

Mascaro, J. (2003). The Bhagavad Gita. New York: Penguin Books.

Maton, A., Hopkins, J., Johnson, S., LaHart, D., Warner, M. Q., \& Wright, J. D. (1997). Exploring Earth Science. Needham, MA: Prentice Hall.

McCance, K. L., \& Huether, S. E. (2014). Pathophysiology: The Biological Basis for Disease in Adults and Children (7th 
ed.). St. Louis, MO: Elsevier.

McManus, B. H., \& Davis, M. J. (1996). Heart Diseases in the Adult. In J. Damjano, \& J. Linda (Eds.), Anderson's Pathology (10th ed., pp. 1156-1338). St. Louis, MO: Mosby-Year Book, Inc.

Millman, B. (1977). Acupuncture Context and Critique. Annual Review of Medicine, 28, 223-236. http://dx.doi.org/10.1146/annurev.me.28.020177.001255

Nani, A., Eddy, C. M., \& Cavanna, A. E. (2011). The Quest for Animal Consciousness. In R. Pemrose, S. Hameroff, \& S. Kak (Eds.), Consciousness and the Universe (pp. 759-772). Cambridge, MA: Cosmology Science Publishers.

National Geography Society (1985). Mysteries of the Ancient World. Washington DC: National Geography Society.

Nelson, K. R. (2011). Do Other Species Express Spirituality. In R. Penrose, S. Hameroff, \& S. Kak (Eds.), Consciousness and the Universe (pp. 682-686). Cambridge, MA: Cosmology Science Publishers.

Nichol, I. (2006). The Essential David Bohm. New York: Rutledge.

Ochsner, K. N., Bunge, S. A., Gross, J. J., \& Gabrieli, J. D. (2002). Rethinking Feelings. An fMRI Study of the Cognitive Regulation of Emotion. Journal of Cognitive Neuroscience, 14, 1215-1229. http://dx.doi.org/10.1162/089892902760807212

Penrose, R. (2005). The Road to Reality: A Complete Guide to the Law of Universe. New York: Vintage Books.

Penrose, R., \& Hameroff, S. (2011). Consciousness in the Universe: Neuroscience, Quantum Space-Time Geometry and Orch OR Theory, Brain and Mind. In R. Penrose, S. Hameroff, \& S. Kak (Eds.), Consciousness and the Universe (pp. 3-42). Cambridge, MA: Cosmology Science Publishers.

Penrose, R., Hameroff, S., \& Kak, S. (2011). Consciousness and the Universe. Cambridge MA: Cosmology Science Publishers.

Persinger, M. A. (2013). Billions of Human Brains Immersed within a Shared Geomagnetic Field: Quantitative Solutions an Implications for Future Adaptations. The Open Biology Journal, 6, 8-13. http://dx.doi.org/10.2174/1874196701306010008

Persinger, M. A. (2014). Schumann Resonance Frequencies Found within Quantitative Electroencephalographic Activity: Implications for Earth-Brain Interactions. International Letters of Chemistry, Physics and Astronomy, 30, 24-32.

http://dx.doi.org/10.18052/www.scipress.com/ILCPA.30.24

Rana, M. H. (1998). Human Embryology. Amsterdam: Hardwood Academic

Reich, D., Green, R. E., Kircher, M., Krause, J., Patterson, M., Durand, E. Y., Viola, B., Briggs, A. W., Stenzel, U., Johnson, P., Maricic, T., Good, J. M., Marques-Bonet, T., Alkan, C., Fu, Q., Mallick, S., Li, H., Meyer, M., Eichler, E. E., Stoneking, M., Richards, M., Talamo, S., Shunkov, M., Derevianko, A. P., Hublin, J. J., Kelso, J., Slakin, M., \& Pääso, S. (2010). Genetic History of an Archaic Hominin Group from Denisova Cave in Siberia. Nature, 468, 1053-1060. http://dx.doi.org/10.1038/nature09710

Ricketts, R. (2015). Traditional Chinese Medicine. http://www.academia.edu/4761813/ln-a-previous-blog-on-Traditional-Chinese-Medicine

Sadava, D., Hillis, D., \& Berembam, M. (2011). Life: The Science of Biology (9th ed.) Gordonsville, VA: W. H. Freeman and Company.

Schrödinger, E. (1935). Discussion of Probability Relation between Separated Systems. Mathematical Proceedings of the Cambridge Philosophical Society, 31, 555-563. http://dx.doi.org/10.1017/S0305004100013554

Schwartz, J., Stapp, H. P., \& Beaureguard, M. (2005). Quantum Physics in Neuroscience and Psychology: A Neurophysical Model of Mind-Brain Interaction. Philosophical Transaction of Royal Society: B, 360, 1309-1327.

Serway, R. A., \& Faughn, J. S. (2000). College Physics (5th ed., 982-983). New York: Saunders College Publishing.

Shin, H. S., Lee, B. C., Choi, S. I., Soh, K. S., Baik, K. Y. et al. (2005). Feulgen Reaction Study of Threadlike Structure (Bonghan Ducts) on the Surface of Mammalian Organs. The Anatomical Record Part B: The New Anatomist, 284B, 35-40. http://dx.doi.org/10.1002/ar.b.20061

Sigal, R. J., Kenny, G. P., Wasserman, D. H., Castanenda-Sceppa, C., \& White, R. D. (2006). Physical Activity/Exercise and Type 2 Diabetes: A Consensus Statement from the American Diabetes Association. Diabetes Care, 29, 1433-1438.

Soh, K. S. (2004). Bonghan Duct and Acupuncture Meridian as Optical Channel of Biophoton. Journal of the Korean Physical Society, 45, 1196-1198.

Soh, K. S. (2009). Bonghan Circulatory System as an Extension of Acupuncture Meridians. Journal of Acupuncture and Meridian Studies, 2, 93-106. http://dx.doi.org/10.1016/S2005-2901(09)60041-8

Soh, K. S. (2015). Hypothesis on the Treatment of Gliomas with Acupuncture at the Primo Node Corresponding to Zusanli (ST 36). Medical Acupuncture, 27, 144-150. http://dx.doi.org/10.1089/acu.2014.1089

Solomon, E. R., Berg, L. R., \& Martin, D. W. (2006). Biology (7th ed.). Belmont, CA: Thompson Books/Cole.

Sonder, B. (1999). Evolutionism and Creationism.. New York: Golier Publishing. 
Stapp, H. P. (1999). Attention, Intention and Will in Quantum Physics. Journal of Consciousness Studies, 6, 143-164.

Stapp, H. P. (2011). Mindful Universe: Quantum Mechanics and the Participating Observer. New York: Springer. http://dx.doi.org/10.1007/978-3-642-18076-7

Stapp, H. P. (2013). Mindful Universe. http://thedivneconspiracy.org/z5256H.pdf

Steding, G. (2009). The Anatomy of Human Embryo: A Scanning Electron-Microscopic Atlas. New York: S. Karger.

Teilhard de Chardin, P. (2008). The Phenomenon of Man. New York: Harper Perennial Modern Thought. https://en.wikipedia.org/wiki/Pierre_Teilhard_de_Chardin

Thomas, K. J., MacPherson, H., Thorp, L., Brazier, J., Fitter, M., Campbell. M. J., Roman, M., Walters, S. J., \& Nicholl, J. (2006). Randomised Controlled Trial of a Short Course of Traditional Acupuncture Compared with Usual Care for Persistent Non-Specific Low Back Pain. British Medical Journal, 333, 623. http://dx.doi.org/10.1136/bmj.38878.907361.7C

Tong, D. (2009). String Theory. http://damtp.ac.uk/user/tong/string/string.pdf

University of California, Berkeley (1991). The Wellness Encyclopedia. Boston, MA: Houghton Mifflin Company.

Warburg, O. (2015). Optimal Breathing Mastery. http://www.breathing.com/articles/cancer.htm

Weil, A. (1995a). Natural Health, Natural Medicine. New York: Houghton Mifflin Company.

Weil, A. (1995b). Spontaneous Healing. New York: Ballantine Books.

Weil, A. (2001). Eating Well for Optimum Health. New York: Gardeners Books.

Weil, A., \& Kabat-Zinn, J. (2001). How to Use Mindful Meditation. http://articles.mercola.com/sites/articles/archive/2001/07/07

Wells, S. (2007). Deep Ancestry. Washington DC: National Geography Society.

West, E. S., \& Todd, W. R. (1961). Textbook of Biochemistry (3rd ed.). New York: The MacMillan Company.

Wikipedia (2015a). Foregut. http://en.wikipedia.org/wiki/Foregut

Wikipedia (2015b). Liver. http://en.wikipedia.org/wiki/Liver

Wikipedia (2015c). Kidney Development. https://en.wikipedia.org/wiki/Kidney_development

Wikipedia (2015d). Urogenital Development. https://web.duke.edu/anatomy/embrology/urogenital/urogenital.html

Wikipedia (2015f). Cosmology. https://enn.wikipedia.org/wiki/Cosmology

Wikipedia (2015g). Evolution. https://en.wikipedia.org/wiki/Evolution

William, R. (1967). The I Ching or the Book of Changes. Rendered into English by C. F. Baynes. London: Rutledge \& Kegan Paul.

Wolpoff, M. H. (2011). Evolution or Extinction of Neanderthal: A Brief History. In R. Penrose, S. Hameroff, \& S. Kak (Eds.), Consciousness and the Universe (pp. 699-712). Cambridge, MA: Cosmology Science Publishers.

Wu, J. Y. (2014). Everyone Vegetarian, World Enriching. Open Journal of Philosophy, 4, 160-165. http://dx.doi.org/10.4236/ojpp.2014.42023

Yi, J. H. (1992). The Third Yeok Hak, 第三의易學 (The Author’s Note: Jeong Yeok as the Third Yeok). Seoul: Te Asian Culture Press. (Text in Korean)

Yogananda, P. (1957). How You Can Talk with God. Los Angeles, CA: Self-Realization Fellowship.

Yogananda, P. (2004). The Second Coming of Christ: The Resurrection of the Christ within You. Los Angeles, CA: SelfRealization Fellowship.

Zhang, J., Webb, D., \& Podlaha, O. (2002). Accelerated Protein Evolution and Original Human Specific Features: Foxp2 as an Example. Genetics, 162, 1825-185. 